\title{
Maps and mapping resources
}

\author{
A guide to select resources on the Web
}

\author{
by Brenda G. Mathenia
}

$\mathrm{T}$ he number of Internet-based maps and mapping resources is increasing and becoming easier to use. However, the difficulty with map sites is in locating them in the vast expanse of cyberspace. Searching for "maps" in a search engine will get you everything from commercial vendors selling you road maps and globes to major companies providing extensive GIS services to map libraries to digital images of maps.

Due to the proliferation of data and .com sites geared toward more advanced users, and in an attempt to make Internet maps more accessible to the average person, I have compiled a select list of Web resources for easily accessing maps.

Included in this selection are collections of scanned and constructed images of maps, as well as a variety of what I call interactive maps. These interactive mapping sites vary in their complexity, but all require some level of input from the user. Most of the sites allow you to print the maps and some allow you to download them. I have found that many of the maps can be saved by right clicking your mouse button and saving to a file. Be aware that many maps are constructed of individual images that may require you to save the map, title, legend, or other ancillary information associated with the map as individual files. Enjoy!

\section{Virtual map collections}

Virtual map collections are Web sites that provide access to a variety of maps that have been digitized and placed on the Web for viewing and, in some cases, downloading. These sites vary in their complexity as well as in the types of maps and information provided.

\section{- Perry-Castañeda Library Map Collec-}

tion. A large, well-organized site, created and maintained by the University of Texas at Austin, that provides electronic access to approximately 4,000 maps for all regions of the world. Maps cover mostly the 19th and 20th centuries though some represent time periods as far back as 980 C.E. The maps are copyright free and are organized by region and special interest areas. Information on viewing and printing maps is provided through a FAQ on the site. Access: http://www.lib.utexas.edu/ maps/.

- The David Rumsey Collection. An ever-growing collection of primarily 18th-and 19th-century North and South American cartographic materials with approximately 5,000 maps currently in place. High-quality digital images showcasing a variety of maps, atlases, globes, and other cartographic items make this an excellent point for research and exploration. Images are easily viewed through your browser or more advanced users can

\section{About the author}

Brenda G. Mathenia is reference librarian/library instruction coordinator at Montana State University, e-mail: mathenia@montana.edu 
download special software available on the Web site. Access: http://www.davidrumsey.com. or click the green areas on the map to zoom into a location of interest. Access: http://terraserver. default.asp.

- The Library of Congress American Memory Map Collections. Provides access to digital representations of maps found in the Geography and Maps Division of the Library of Congress and covering the years 1500-1999. Search using keywords or browse the subject, title, creator, and geographic indexes to find maps that are focused on Americana and cartographic treasures found in the Library of Congress. Access. http://memory.loc.gov/ammem/gmdhtml/ gmdhome.html.

- The CIA World Factbook. The online version of a classic resource. Here you will find quality geographic information on countries and high-quality maps of regions and individual countries of the world. Map images are available in JPEG or PDF format. Access. http:/ www.cia.gov/cia/publications/factbook.

- Goode's World Atlas. The online, though limited, version of the classic atlas. Select a specific theme to map (world refugees, energy production, precious metals, etc.) or print a map of a U.S. state. Individual maps of non-U.S. locations are not available. Maps are available as PDF files and provide highquality print results. Access: http:// www.goodesatlas.com/downloadmaps.htm.

- United Nations Cartographic Section. Provides access to more than 100 non-U.S. maps organized by region and country. Maps open as PDF files, so printing is easy. You will also find peacekeeping maps and a select number of thematic maps at this site. Access: http://www.un.org/Depts/Cartographic/english/.

- National Geographic Map Machine. A joint project of National Geographic and ESRI, which provides a multitude of mapping products. Search for a location or use the Map Categories along the left side of the page to direct you to mapping options. Maps print well, though titles/ legends are not always clear. The popularity of the site presents challenges in connecting but once in, you can get some quality maps. Access: http://plasma.nationalgeographic.com/ mapmachine/index.html.

- Microsoft's Terra Server. Provides free public access to maps and aerial photography of the United States. Search for a specific city
- Topozone. This commercial site (part of the USGS Digital Cartographic Business Partner program) provides access to USGS quadrangle maps for personal use. Search by map name, by name of a city or place, or even by the name of a geographic feature. The maps have good resolution on screen and you can pan the four directions from the starting point to get a look at the map. Maps print reasonably well. You can also pick a new scale on the fly and zoom in or out as you please. Access: http://www.topozone.com.

\section{IonoZnone.com}

- MapTech MapServer. This commercial site provides access to topographic maps, nautical charts and aerial photos, called NavPhotos, which cover coastal regions exclusively. This site allows the user to search for maps by place name and state. Multiple map scales are available, and placing your cursor over the map image will generate coordinates for that point on the map. Maps print well and there is an e-mail option for sending the image to a friend. Access: http:// www.maptech.com.

\section{Interactive mapping sites}

There are two basic types of Web sites that fall into this category: sites that enable users to map street addresses and those that permit the mapping of data such as demographic data, health statistics, or earth sciences data.

\section{Street mapping sites}

These are the Web sites that many people are already familiar with and that are the easiest to access and use. Simply put in a city or an address and click the button to be provided with a map of your desired location. Many of these sites provide driving directions between cities or door-to-door directions (you supply the addresses).

- MapQuest. An easy-to-use, popular site that includes three main components: online maps, driving directions, and travel guides. The maps are clean, accurate, and a printerfriendly map format is provided. Try the In- 


\section{MAPQUEST" \\ whore to go, how to get there!}

ternational Web Sites link at the bottom of the page to get street maps and driving directions for England, France, and Germany. The World Atlas and Road Atlas links provide additional map resources and some are supplemented with aerial photos. Access: hitp:// www.mapquest.com.

- MapBlast! This site maps addresses or cities and will produce driving directions. Map icons are somewhat customizable, and in larger urban areas offers traffic reports for the region. This site also provides local weather reports (from Ann-Arbor based Weather Underground). Access: http://www.mapblast.com.

- Make Quick Maps (from ESRI, the makers of ArcView GIS software). This site uses a product called ArcData Online, which allows the user to create maps of the United States based on street addresses. This site also allows the generation of general maps of Europe or the world. For major non-U.S. cities, use the zoom function and you will be rewarded with street maps, though they are not as detailed as the ones in MapQuest or Yahoo Maps. You won't find travel guides or weather reports here, but the maps can be saved in GIF format. Access: http:// www.esri.com/data/online/quickmap.html.

- Yahoo Maps. This is Yahoo's contribution to street mapping with a similar interface and features as the other sites. This is the only street mapping site that contains detailed Canadian maps. Access: http:// maps.yahoo.com/py/maps.py.

\section{Data mapping sites}

The following Web sites provide users with a much more hands-on approach to mapping. These sites allow the user to actually pick and choose, within limits, what information will be displayed on the maps they create. These sites allow mapping of demographic or socioeconomic data. They also require
International Earth Science Information Network (CIESIN), is an interactive mapping application for data

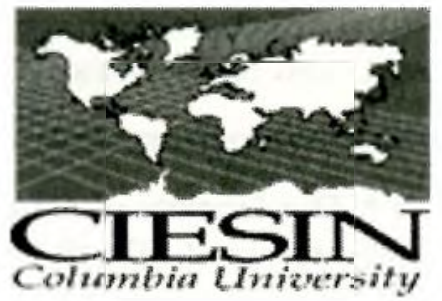
from the 1990 U.S. Census of Population and Housing. Data from the 2000 Census will be included as it becomes available. Selected variables may be mapped at the levels of county, county subdivision, census tract, and blockgroup. It creates simple but effective maps. Different editions (Java and Non-Java) are provided for different connection speeds. Directions can be cryptic and output options are limited, but screen shots of the maps you create work well in documents. Also available from this site is the U.S.-Mexico DDViewer. Access: http://plue.sedac.ciesin. org/plue/ddviewer/.

- Tiger Mapping Service. This site from the U.S. Census Bureau is one of the original interactive mapping sites on the Web. Users can map a limited number of census variables to geographic map areas, such as U.S. Congressional Districts, zip code areas, and more standard census and blockgroup areas. Cultural features, such as highways and parks, are also available for mapping. Search by city or provide a specific set of coordinates. Major updates are not planned for this site, but it remains a useful resource. Access: http:// tiger.census.gov/cgi-bin/mapbrowse-tbl.

- American Fact Finder. This site from the U.S. Census Bureau is the site to visit for 2000 Census data and provides both reference maps, which show basic boundary information (cities, counties, census tracts, etc.) and thematic maps. The Thematic Map option allows the user to select the geographic area of coverage, select from a limited number of themes, and then view the results. Changing items, such as geography, theme and data sets, is done following a series of steps with straightforward directions. Data tables are also available at this site. Output more involvement on the part of the user, which is something to consider when using or recommending these sites.

- Demographic Data Viewer (DDViewer). This site, from the Center for options include printing and saving to a file. Access: http://factfinder.census.gov.

- National Atlas of the United States. This site is from the U.S. Geological Survey (continued on page 925) 


\section{LIBRARIES UNLIMITED}

\section{NEW AND FORTHCOMING RELEASES}

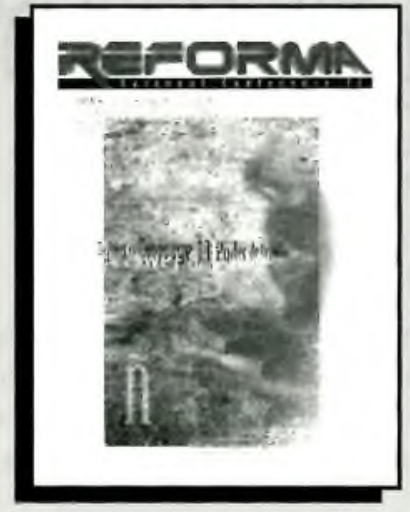

The Power of Language/EI
Poder de la Palabra: Selected
Papers from the Second
REFORMA National Conference

REFORMA • LILLIAN CASTILLO-SPEED, EDITOR

Committed to promoting Spanish-language and Latino oriented services and resources in libraries, this selection of 20 papers was compiled at the Second REFORMA National Conference by experts in the Spanish-speaking field. The work covers a wide range of thought-provoking ideas, issues in Latino library services, leadership, practical applications, programs, and bibliographical resources. Great for librarians, library staff, and managers who have an obligation to provide quality library services to the U.S. Latino community.

2001 ca.230p. $6 \times 9$ paper ISBN 1-56308-945-9 $\$ 35.00$

\section{Content Evaluation of Textual CD-ROM and Web Databases}

\section{PÉTER JACSO - Winner of the ASIS Outstanding Information Science Teacher Award}

This richly illustrated book provides an invaluable guide for evaluating a variety of widely used database types, including abstracting and indexing, directory, full-text, and page-image databases available in online and/or CD-ROM formats. A must for library professionals!

2001 ca.337p. 8 ${ }^{\circ} \times 11$ paper ISBN 1-56308-737-5 $\$ 37.00$

\section{Digital Preservation and Metadata History, Theory, Practice}

SUSANS. LAZINGER

This book addresses critical issues of preservation, showing you everything you need to effectively protect your digital resources-from problems of obsolescence, to responsibilities, methods of preservation, cost, and metadata formats. It also describes numerous national and international institutions that provide frameworks for digital libraries and archives. A long-needed text for anyone involved in the preservation of digital information, this book is indispensable in understanding today's methods and practices, intellectual discourse, and preservation guidelines. A must for librarians, archiving professionals, faculty and students of library science, administrators, and corporate leaders!

2001 ca.365p. $6 \times 9$ cloth ISBN 1-56308-777-4 \$55.00

Educational Technology: The Development of a Concept

ALAN JANUSZEWSKI

2001 xxiii, 137p. $7 \times 10$ paper

ISBN 1-56308-749-9 \$48.00
Issues for Libraries and Information Science in the Internet Age BRUCE A. SHUMAN

2001 xviii, 227p. $6 \times 9$ paper

ISBN 1-56308-805-3 \$45.00 
about who benefits from particular interpretations of the news. Out of these discussions can emerge important research questions that may conflict with student views and values and may create teachable moments.

Our current conception of information literacy instruction focuses on teaching the objective and "safe" aspects of research. For instance, we typically help students focus their research on euthanasia; find books and fulltext articles on the topic; distinguish between popular and scholarly sources; and evaluate Web-based information. However, we rarely have an opportunity to generate meaningful connections between this topic and the lives of students or help students question the nature of discourse that takes place.

In the future, information literacy programs will emphasize the whys as well as the hows. By focusing on the whole person, successful programs will begin with real student concerns and help students understand how their issues relate to the larger world. Second, they

\section{("Internet Resources" cont. from page 912)}

and is an online "cousin" to the original National Atlas of the United States produced in the 1970s. Choose "Atlas Maps" to use the National Atlas of the United States produced in the 1970s. Choose "Atlas Maps" to use the National Atlas Map Browser to build, view, and print maps using a variety of information layers. There are a number of multimedia maps available at this site that combine graphical representations of data with animation as well as links for finding additional information. While there are a limited number of mapping options, users can download $\mathrm{Na}$ tional Atlas map layers for personal use or find information on paper maps. Access. http://www.nationalatlas.gov/.

- Wetlands Interactive Mapper Tool. This site from the National Wetlands Inventory Center of the U.S. Fish and Wildlife Service provides access to National Wetlands Inventory Maps in digital format. Select a county, city, zip code, refuge, or lat/long and submit your query. Where available, link to aerial photography from Microsoft's TerraServer or view a topographic map of the area. While these will not replace the detailed paper maps, the site is a nice place to start for wetlands information. Not all locations are available, will emphasize participation in the community as a way to further facilitate meaningful connections. Third, they will encourage students to discover and challenge the unquestioned, taken-for-granted assumptions by which we all live. By necessity, these programs will focus on the advocacy of real-world issues as well as on methodology.

We are called to participate in shaping an information future that improves the world. We can play a crucial role in the future-if we choose to play. Certainly, others would don our apparel in this new age and disguise information literacy in a cloak of academic remoteness and objectivity.

However, that is past. The time has come to take risks in developing an information literacy that matters to students because it reaches out to the world to solve real problems, because it challenges our assumptions, because it changes the world. Time is passing faster than we know. Let us not miss our opportunity. The world calls us.

so check out the Current NWT Status Map from the main page to find out if digital maps are available in your area. Access: http:// wetlands.fws.gov/mapper_tool.htm.

\section{Other sites for locating maps}

- Oddens' Bookmarks. This is a classic in the world of geography not only for providing links to map resources, but links to the entire world of cartography and geography. Select Browse, then Maps and Atlases and choose the type you want to find. There are 5,914 Electronic Atlases and 149 in the Online Map Creating category. Long lists but some real gems can be found here. Access: http://oddens.geog.uu.nl.

- Maps on Other Web Sites. This is a nice listing of maps by categories available on the Web. Access: http://www.lib.utexas. edu/maps/map_sites/map_sites.html.

- State Data Centers. This site provides information for state data centers in all 50 states, but often provides canned maps that focus on socio-economic data or natural resources. Note that not all states provide Web sites, data, or maps. It is a good starting point when searching for maps/data of census information for a particular state. Access: http://www.census.gov/sdc/www/ 